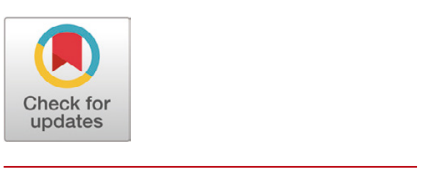

Received: April 20, 2020

Revised: May 8, 2020

Accepted: May 16, 2020

*These authors contributed equally to this work.

${ }^{\dagger}$ Corresponding author

Dae-Sung Kim

Department of Biotechnology, Korea

University, Seoul 02481, Korea.

Tel: +82-2-3290-3013

Fax: +82-2-3290-3040

E-mail: sonnet10@korea.ac.kr

Copyright $\odot 2020$ The Korean Society of Developmental Biology.

This is an Open Access article distributed under the terms of the Creative Commons Attribution Non-Commercial License (http://creativecommons.org/licenses/ by-nc/4.0/) which permits unrestricted non-commercial use, distribution, and reproduction in any medium, provided the original work is properly cited.

ORCID

Byeong-Min Jeon

https://orcid.org/0000-0002-3401-1053 Gyu-Bum Yeon

https://orcid.org/0000-0002-0160-8275 Hui-Gwan Goo

https://orcid.org/0000-0001-5835-8353 Kyung Eun Lee

https://orcid.org/0000-0001-5791-0046

Dae-Sung Kim

https://orcid.org/0000-0001-6690-5943

Conflict of interests

The authors declare no potential conflict of interest.

\section{PVDF Nanofiber Scaffold Coated with a Vitronectin Peptide Facilitates the Neural Differentiation of Human Embryonic Stem Cells}

\author{
Byeong-Min Jeon ${ }^{1,2 *}$, Gyu-Bum Yeon ${ }^{1,2 *}$, Hui-Gwan Goo ${ }^{3}$, Kyung Eun Lee ${ }^{4}$, \\ and ${ }^{\dagger}$ Dae-Sung Kim ${ }^{1,2,5 *}$ \\ ${ }^{1}$ Dept. of Biotechnology, College of Life Sciences and Biotechnology, Korea University, Seoul 02841, Korea \\ ${ }^{2}$ Institute of Animal Molecular Biotechnology, Korea University, Seoul 02841, Korea \\ ${ }^{3}$ AMO Lifescience Co., Ltd., Seoul 06527, Korea \\ ${ }^{4}$ Advance Analysis Center, Korean Institute of Science and Technology, Seoul 02792, Korea \\ ${ }^{5}$ Dept. of Pediatrics, Korea University College of Medicine, Seoul 08308, Korea
}

\section{Abstract}

Polyvinylidene fluoride (PVDF) is a stable and biocompatible material that has been broadly used in biomedical applications. Due to its piezoelectric property, the electrospun nanofiber of PVDF has been used to culture electroactive cells, such as osteocytes and cardiomyocytes. Here, taking advantage of the piezoelectric property of PVDF, we have fabricated a PVDF nanofiber scaffolds using an electrospinning technique for differentiating human embryonic stem cells (hESCs) into neural precursors (NPs). Surface coating with a peptide derived from vitronectin enables hESCs to firmly adhere onto the nanofiber scaffolds and differentiate into NPs under dual-SMAD inhibition. Our nanofiber scaffolds supported the differentiation of hESCs into SOX1-positive NPs more significantly than Matrigel. The NPs generated on the nanofiber scaffolds could give rise to neurons, astrocytes, and oligodendrocyte precursors. Furthermore, comparative transcriptome analysis revealed the variable expressions of 27 genes in the nanofiber scaffold groups, several of which are highly related to the biological processes required for neural differentiation. These results suggest that a PVDF nanofiber scaffold coated with a vitronectin peptide can serve as a highly efficient and defined culture platform for the neural differentiation of hESCs.

Keywords: Polyvinylidene fluoride (PVDF), Nanofiber, Vitronectin, Neural differentiation, hESCs, Dual-SMAD inhibition

\section{INTRODUCTION}

Neural precursors (NPs) derived from human embryonic stem cells (hESCs) are highly proliferative and can give rise to three types of cells of the central nervous system (CNS): neurons, astrocytes, and oligodendrocytes. The primitive nature of NPs enables them to be engineered to form specific neural cells found in particular regions of the CNS, such as spinal motor neurons and midbrain dopaminergic neurons (Kriks et al., 2011; Du et al., 2015); this is a unique property of NPs derived from hESCs that 
Acknowledgements

This work was supported by grants from

the National Research Foundation (NRF)

funded by the Korean government

(2015R1D1A1A01056649 and

2017M3A9F8032402) and a research grant from

Korea University.

Authors' contributions

Conceptualization: Kim DS.

Data curation: Jeon BM, Yeon GB.

Formal analysis: Jeon BM, Yeon GB.

Methodology: Lee KE, Goo HG.

Writing - original draft: Kim DS.

\section{Ethics approval}

This article does not require IRB/IACUC approval

because there are no human and animal participants. is nearly impossible to see in neural stem cells from fetal and adult tissues. In this regard, hESCderived NPs are an invaluable source for biomedical applications.

Technologies for the derivation of NPs from hESCs have been intensively developed. Based on their experience with mouse ESC culture, scientists have developed several methods for neural induction of hESCs: 1) the embryoid body (EB)-based method, in which EBs made using a suspension culture of hESCs are attached to generate a "neural rosette," a characteristic morphology of primitive NPs, under neural tissue-inducing culture conditions (Zhang et al., 2001) and 2) coculture of hESCs with mouse stromal cell lines, such as PA6 and MS5, which is often employed to generate neural rosettes and NPs from hESCs (Perrier et al., 2004). More recently, a great advancement has been achieved by adopting the concept of neural development in vertebrate embryos. The simultaneous inhibition of cellular signals that suppress neuroectodermal development - bone morphogenetic protein (BMP) and transforming growth factor- $\beta$ (TGF- $\beta$ ) signals - could robustly enhance the efficiency of neural differentiation from hESCs (Chambers et al., 2009). This strategy, often referred to as "dual-SMAD inhibition," has even helped overcome the differentiation propensity observed in many hESC lines that have proven stubborn to differentiate into cells of neural lineage (Kim et al., 2010). Due to the robustness of the results obtained using it, this method has now become the most popular protocol for generating NPs from hESCs.

While the involvement of cell signaling pathways, such as BMP and TGF- $\beta$ pathways, in neural induction has been intensively studied for decades, the contribution of the extracellular environment to neural induction has just begun to attract the attention of stem cell scientists. The extracellular matrix (ECM) greatly influences the survival, proliferation, and differentiation of stem cells (Niklason, 2018). For instance, specific ECM molecules, such as laminin and fibronectin, influence neural differentiation and neurite outgrowth through cellular signals mediated by integrin receptors ( $\alpha 6 \beta 1$ or $\alpha 5 \beta 1$ ). In addition to such roles, the physical properties of ECMs, such as stiffness and elasticity, have also been discovered to be important for differentiation of hESCs toward a neural lineage (Akhmanova et al., 2015) and determination of the fate of specific neural cells (Smith et al., 2018). More recently, synthetic nanofibers, inspired by the nano-architecture of natural ECM, have been shown to enhance the neural differentiation of hESCs (KarbalaeiMahdi et al., 2017), indicating the role of extracellular environment in neural lineage specification.

In this study, we sought to develop a new platform for the neural differentiation of hESCs by creating a nanofiber scaffold composed of a biocompatible and electroactive material, polyvinylidene fluoride (PVDF). In particular, we adopted an electrospinning technology to produce a scaffold of nanofibers with a defined diameter and immobilized a vitronectin-derived peptide on the scaffold to maximize the adherence of $\mathrm{hESC}$. When $\mathrm{hESC}$ s were made to differentiate under dual-SMAD inhibition, we found that the nanofiber scaffold facilitated neural differentiation more efficiently than Matrigel, a conventional ECM, and the difference in efficiency was statistically significant. RNA sequencing (RNAseq) analysis revealed several key molecular changes relevant to the neural development of hESCs grown on our PVDF nanofiber scaffold. These results substantiate the utility of the PVDF nanofiber scaffold for the differentiation of NPs from hESCs and its potential as a new platform for future biomedical applications.

\section{MATERIALS AND METHODS}

\section{Fabrication of PVDF nanofiber scaffolds}

Preparation of the PVDF nanofiber scaffolds was performed by AMO Greentech (Gimpo, Gyuonggi-do, Korea) and AMO Lifescience (Seoul, Korea) using a spin-coated PVDF solution 
dissolved in a dimethylacetamide solvent (Sigma, St Louis, MO, USA). Briefly, the spinning solution was loaded in a syringe capped with a nozzle tip whose outer diameter was $0.9 \mathrm{~mm}$; it was then electro-sprayed at a power of $20-40 \mathrm{kV}$ and a flow rate of 50-100 $\mu \mathrm{g} / \mathrm{mL}$. The nanofibers were compressed using lamination, with heat of $80^{\circ} \mathrm{C}-120^{\circ} \mathrm{C}$. After drying at room temperature (RT), the compressed nanofiber scaffold was punched out in a circular pattern and fixed to the bottom of a 6-well plate using a polyethylene terephthalate (PET) film.

\section{Preparation of a recombinant MAP-vitronectin fusion protein}

Mussel adhesive protein (MAP) is a natural glue that is derived from marine mussel and is often used for cell adhesion (Lee et al., 2011). We first cloned a plasmid with a gene encoding a recombinant MAP fusion protein composed of fp-1, as described elsewhere (Hwang et al., 2007). Then, based on the published amino acid and cDNA sequences available on the NCBI website (Gene ID: 7448), we cloned a plasmid encoding a fusion protein of MAP and a heparin-binding peptide of vitronectin that has been shown to support the attachment of hESCs (herein, VNm) (Klim et al., 2010). The recombinant hybrid MAP-VNm fusion protein was expressed in E. coli $\left(\right.$ Rosetta-gami $\left.{ }^{\circledR}\right)$ (Thermo Fisher Scientific, Waltham, MA, USA) using a $14 \mathrm{~L}$ fermentor and harvested as inclusion bodies. Next, the inclusion bodies were recovered as a solution of functional peptides in distilled water by a conventional procedure (Palmer \&Wingfield, 2004).

\section{Surface coating with vitronectin-derived peptide}

Before coating its surface with the recombinant MAP-VNm fusion protein, we activated the nanofiber scaffold with a $10 \mathrm{mM}$ solution of 1-ethyl-3-(3-dimethylaminopropyl) carbodiimide (EDC) (AK Scientific, Union City, CA, USA) and $10 \mathrm{mM} \mathrm{N}$-hydroxysuccinimide (NHS) (AK Scientific) in $20 \mathrm{mM}$ sodium acetate buffer ( $\mathrm{pH}$ 6.5) at RT for $30 \mathrm{~min}$. We then added a solution of MAP-VNm fusion protein $(0.05 \mu \mathrm{g} / \mathrm{mL})$ to the activated scaffold for $30 \mathrm{~min}$ at RT. After three washes with distilled water for $10 \mathrm{~min}$, the scaffold coated with the fusion protein was dried and stored at RT before use. The schematic processes of scaffold fabrication and surface coating are illustrated in Fig. 1A.

\section{Culture and differentiation of hESCs}

An hESC line, WA09 (conventionally known as H9), was obtained from WiCell (USA). The hESCs were cultured on a Matrigel ${ }^{\circledR}$ (Thermo Fisher Scientific)-coated 6-well plate in StemMACS ${ }^{{ }_{1}}$ PS-Brew XF medium (Miltenyi Biotec, San Diego, CA, USA) (herein, hESC culture medium) and expanded by enzymatic passaging, a conventional expansion technique. For neural differentiation, we employed the dual-SMAD inhibition strategy previously described by Chambers et al. (Chambers et al., 2009), with slight modifications. Briefly, we plated hESCs on Matrigel or nanofiber scaffolds at the density of $1 \times 10^{4} \mathrm{cell} / \mathrm{cm}^{2}$ in $\mathrm{hESC}$ culture medium containing $10 \mu \mathrm{M}$ Y-27632 (Sigma). From the day 1 of differentiation, we began to add $250 \mathrm{nM}$ of LDN193189 (StemCell technology, Vancouver, BC, Canada) and $10 \mu \mathrm{M}$ of SB431542 (Sigma) in the hESC culture medium and cultured the hESCs for 8 days. On day 4, we switched the culture medium from hESC culture medium to neural induction medium (DMEM/F12 medium supplemented with $1 \times$ N2, $1 \times$ non-essential amino acid (all from Thermo Fisher Scientific) and $20 \mathrm{ng} / \mathrm{mL}$ bFGF (Peprotech, Rocky Hill, NJ, USA)). The medium was replenished on alternate days. On day 8, the cells were either harvested for RNA preparation or dissociated by Accutase (Thermo Fisher Scientific) and replated on Matrigel-coated $12 \mathrm{~mm}$ coverslips for immunostaining. For further differentiation, on day 8 , the cells were dissociated and replated on a Matrigel-coated coverslip at the density of $5 \times 10^{4} \mathrm{cell} / \mathrm{cm}^{2}$. The cells (NPs) were induced to differentiate in neural 

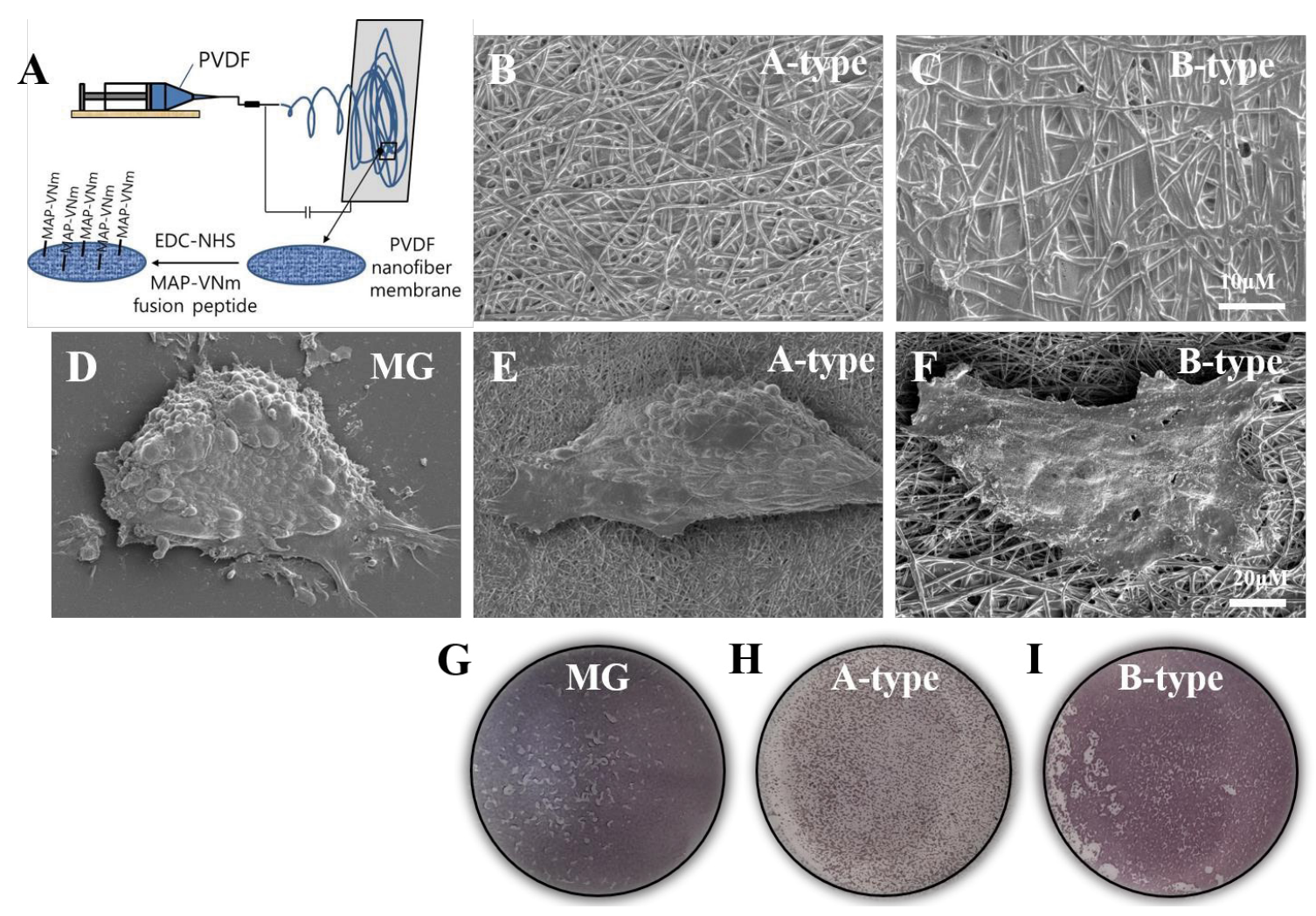

Fig. 1. Characterization on PVDF nanoscaffolds. (A) A schematic illustration for the processes of scaffold fabrication and surface coating. (B, C) EM images of nanofiber scaffolds showing that fibers were evenly distributed, and that their diameters were constant. (D-F) Representative EM images of hESCs grown on various substrates. Note that morphology of the cells grown on the B-type scaffold was flat and spread compared to those on the A-type scaffold. (G-I) Alkaline phosphatase staining of cells grown on various substrates. MG, Matrigel; EM, electron microscopy.

differentiation medium (DMEM/F12 supplemented with $1 \times \mathrm{N} 2,1 \times \mathrm{B} 27,1 \times$ non-essential amino acid, as well as $10 \mathrm{ng} / \mathrm{mL}$ BDNF (Peprotech) and $20 \mu \mathrm{M}$ ascorbic acid (Sigma)) for 2 weeks.

\section{Immunostaining}

Cell samples were fixed in 4\% paraformaldehyde for 15 min at RT and washed with phosphate buffed saline (PBS). After permeabilization with $0.05 \%$ Triton X-100 in PBS for 5 min, the samples were blocked using $2 \%$ bovine serum albumin solution for at least one hour and then incubated with primary antibodies (see below) overnight at $4^{\circ} \mathrm{C}$. After that, the samples were thoroughly washed with PBS thrice and then incubated with appropriate secondary antibodies conjugated with a fluorescent dye (Alexa fluor ${ }^{\circledR} 488$ or 594, Thermo Fisher Scientific) for 30 min at RT. After washing with PBS, the coverslips were mounted on glass slides using a 4',6-diamidino2-phenylindole (DAPI)-containing mounting solution (Vector laboratory, Burlingame, CA, USA). The cell images were captured using a fluorescence microscope (IX71) equipped with a digital camera (DP71) (both from Olympus, Tokyo, Japan). Primary antibodies used in this study were as follows: SOX1 (rabbit, 1:200; R\&D Systems, San Diego, CA, USA), SOX2 (rabbit, 1:200; Thermo Fisher Scientific), NESTIN (Mouse, 1:200; Thermo Fisher Scientific), TUJ1 (Mouse, 1:1,000; BioLegend, San Diego, CA, USA), GFAP (Rabbit, 1:1,000; Dako, Carpinteria, CA, USA), A2B5 (Mouse, 1:200; Thermo Fisher Scientific), and NG2 (Rabbit, 1:100; Thermo Fisher Scientific). 


\section{Quantitative reverse transcription-polymerase chain reaction (qRT-PCR)}

Total RNAs were extracted using the Easy-Spin ${ }^{\circledR}$ total RNA purification kit (iNtRON Biotechnology, Seongnam, Gyeonggi-do, Korea) according to the manufacturer's instruction. One microgram of the total RNAs was used to synthesize cDNAs using the Power cDNA Synthesis kit (iNtRON Biotechnology). Next, qRT-PCR was performed on the StepOnePlus ${ }^{\circledR}$ real-time PCR system (Thermo Fisher Scientific) using the Fast SYBR ${ }^{\circledR}$ Green Master Mix (Thermo Fisher Scientific). Primer sequences are listed in Table 1.

\section{Electron microscopy (EM)}

The cell specimens were fixed with $2.5 \%$ glutaraldehyde solution and incubated at $4{ }^{\circ} \mathrm{C}$ overnight followed by washing with $0.1 \mathrm{M}$ cacodylate buffer ( $\mathrm{pH}$ 7.2). The cells were then incubated in $1 \%$ osmium tetroxide for 1 hour, washed with distilled water, and dehydrated gradually using increasing concentrations of ethanol (50\%, 70\%, 90\%, and 100\%). After drying inside a fume hood, the cell specimens were mounted on SEM stubs followed by platinum coating with a sputter coater (E1045, Hitachi, Tokyo, Japan). Surface imaging was carried out using the ETD detector of an SEM (TeneoVS, FEI) in the SE mode at $2 \mathrm{kV}$.

\section{RNAseq and comparative transcriptomic analysis}

Total RNA was isolated as previously described and was submitted to MACROGEN, Korea for paired-end sequencing; over 60 million reads were generated. Raw FASTQ files were trimmed for adapters using TrimGalore (Krueger, 2020), quantified at the transcript level against an Ensembl catalog using Salmon (Patro et al., 2017), aggregated to the gene level using tximport (Soneson et al., 2015), and delivered to DESeq2 (Love et al., 2014) for further analysis using a standard pipeline. A correlation plot was prepared using ggplot2 (v3.3.0), and a heatmap was prepared using pheatmap (v1.0.12). Gene ontology analysis was performed using Metascape (Zhou et al., 2019).

\section{Data presentation and statistical analysis}

The experiments were performed in triplicate at the least, and data were presented as mean $\pm S E M$. Experimental data was analyzed with one-way analysis of variance (ANOVA) followed by Bonferroni's post hoc test. $p<0.05$ was considered to be statistically significant.

\section{RESULTS}

\section{Attachment of hESCs on the PVDF nanofiber scaffolds}

To examine the behavior of hESCs grown on the PVDF nanofiber scaffolds, we first created

Table 1. A list of primer sequences

\begin{tabular}{ccc}
\hline \hline Target gene & Forward primer & Reverse primer \\
\hline ACTB & CAC CAT TGG CAA TGA GCG GTT C & GG TCC TTG CGG ATG TCC ACG T \\
SOX1 & TGAACG CCT TCA TGG TGT GGT C & GCG CGG CCG GTA CTT GTAAT \\
SOX2 & GCT ACA GCA TGA TGC AGG ACC A & TCT GCG AGC TGG TCA TGG AGT T \\
PLZF & GAG CTT CCT GAT AAC GAG GCT G & AGC CGC AAA CTA TCC AGG AAC C \\
PAX6 & CTG AGG AAT CAG AGAAGA CAG GC & ATG GAG CCA GAT GTG AAG GAG G \\
NANOG & CTC CAA CAT CCT GAA CCT CAG C & CGT CAC ACC ATT GCT ATT CTT CG \\
NESTIN & TCAAGA TGT CCC TCA GCC TGG A & AAG CTG AGG GAA GTC TTG GAG C \\
\hline
\end{tabular}


two types of PVDF membranes with fiber diameters of $200 \mathrm{~nm}$ (referred to as A-type) and 700 $\mathrm{nm}$ (B-type), respectively. Our preliminary observation revealed that the electrospun PVDF nanofiber scaffolds were not compatible for the attachment of hESCs possibly due to their hydrophobic nature (data not shown). Therefore, to endow the PVDF nanofiber scaffolds with the ability to support the attachment of hESCs, we made a biochemical modification in the scaffolds by immobilizing a peptide motif derived from vitronectin $(\mathrm{VNm})$ that was shown to support the attachment and growth of hESCs (Klim et al., 2010). In particular, we immobilized the VNm on the surface of the scaffold by creating a fusion peptide with MAP and combining it using a recent technology that involves a peptide-acrylate surface coating process (Fig. 1A) (Hwang et al., 2007; Melkoumian et al., 2010) (see the details in Materials and Methods). As shown in Fig. 1B and C, EM showed that each PVDF nanofiber scaffold was composed of nano-sized fibers with a relatively constant diameter and without any cobble-stone-like aggregation. The hESCs seeded and cultured on each scaffold were observed to be as adherent as on Matrigel (Fig. 1D-F), indicating the functional immobilization of the VNm peptide. Interestingly, the shape of hESC colonies on the A-type scaffold appeared similar to the shape of colonies on Matrigel, which is dome-shape, whereas the colonies of hESCs on the B-type scaffold were spread out and had a flat-shape (Fig. 1D-F). As PVDF nanofiber scaffolds are opaque, bright-field microscopy could not be used to observe the morphology of the cells; thus, AP staining was performed, and the morphology of cells was observed by EM.

\section{Neural differentiation of hESCs on the PVDF nanofiber scaffolds}

To test whether the PVDF nanofiber scaffolds facilitate the neural differentiation of hESCs, we cultured hESCs on either nanofiber scaffolds or Matrigel (as a control ECM) under dual-SMAD inhibition and compared the efficiency of neural differentiation. On day 8 of differentiation, we detached the cells from the scaffolds and Matrigel by enzymatic dissociation, and replated them on a Matrigel-coated coverslip for immunocytochemistry. Immunostaining with an antibody against SOX1, a definitive marker for NPs, revealed that $81.3 \pm 0.3 \%$ of the cells in the Matrigel group had strong immunoreactivity (Fig. $2 \mathrm{~A}$ and $\mathrm{G}$ ), which is similar to the results of previous studies (Chambers et al., 2009). In contrast, we observed that of the total cells on the A-type and B-type scaffolds, $91 \pm 2.5 \%$ and $86 \pm 1.2 \%$ were positive for SOX1, respectively (Fig. 2B, C, and G). More importantly, the yield of SOX1-positive cells on both the nanofiber scaffolds was significantly higher than that on Matrigel (Fig. 2G) ( $p=0.008$ for A-type and $p=0.04$ for B-type, $\mathrm{n}=3$ in each group, one-way ANOVA test with Bonferroni's post hoc test). In addition, almost all cells were also positive for SOX2 and NESTIN, ensuring their fate as NPs (Fig. 2D-F). Relative gene expression analysis for neural precursor markers, such as NESTIN and PLZF, also revealed the significantly (in case of NESTIN) increased expression of the markers in the nanofiber scaffold groups compared to that in the Matrigel group (Fig. 2H and I). Collectively, these results suggest that PVDF nanofiber scaffolds coated with $\mathrm{VNm}$ cause better neural differentiation of hESCs than the conventional ECM(Fig. 1G-I).

\section{NPs differentiated on the PVDF nanofiber scaffold retain their differentiation potential}

Next, we examined whether the NPs differentiated on nanofiber scaffolds retain their neural stem cell differentiation potential. We further differentiated NPs by culturing them in neural differentiation medium. In two weeks, NPs generated on the PVDF nanofiber scaffolds differentiated into TUJ1-positive neuronal cells, GFAP-positive glial cells, and NG2/A2B5-double positive oligodendrocyte precursor cells (Fig. 3). Of the NPs generated on the PVDF nanofiber scaffolds, TUJ1-positive cells were most frequently observed, followed by NG2/A2B5-double 

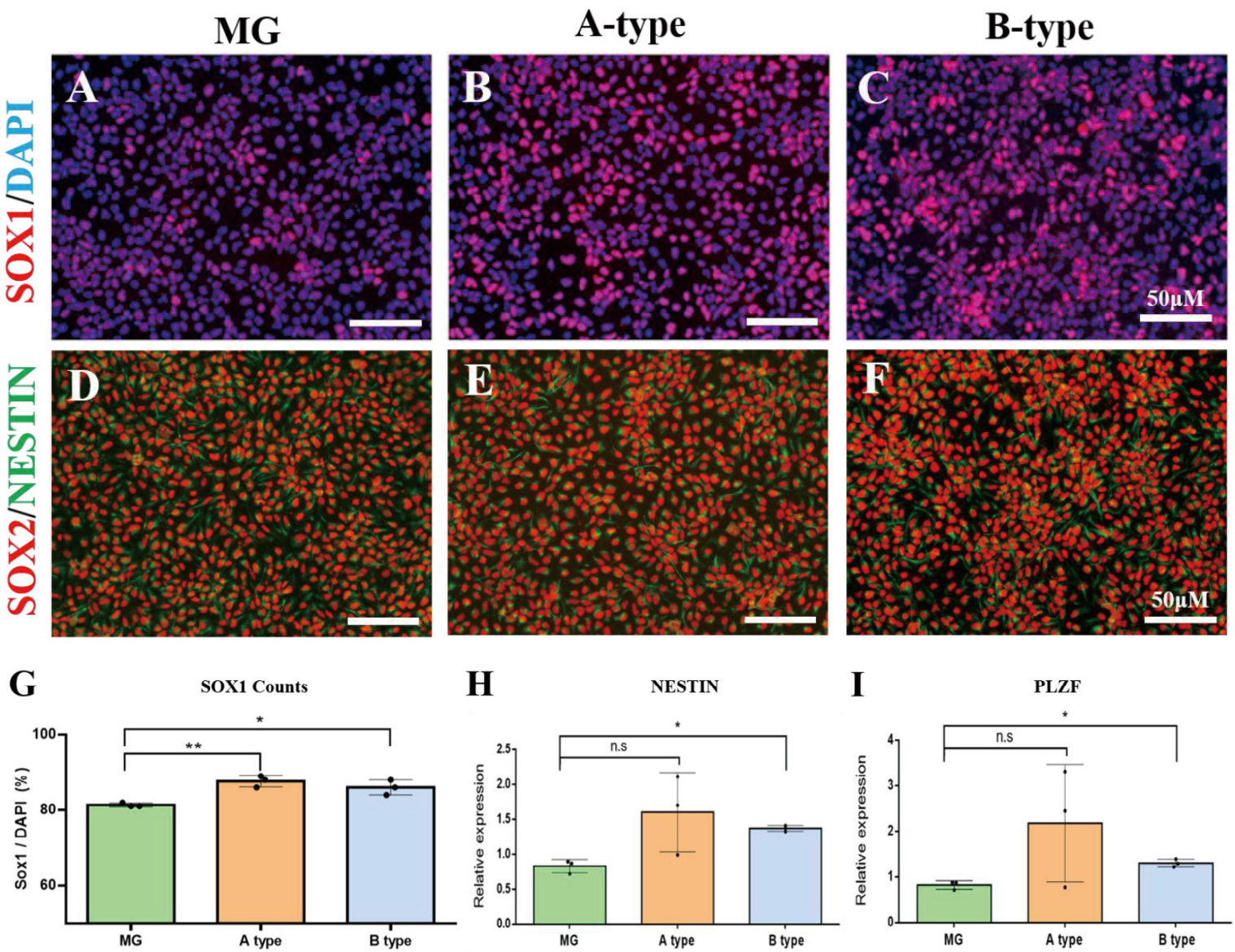

Fig. 2. Neural differentiation of PVDF nanoscaffolds. (A-C) Representative immunofluorescence images of SOX1-positive cells differentiated on various substrates. (D-F) Immunofluorescence images of SOX2 and NESTIN-positive cells. Almost all cells were positive for both markers, suggesting the robustness of dual-SMAD inhibition paradigm for neural induction. (G) Counting result for SOX1-positive cells. Note that the number of SOX1-positive cells was significantly increased in both A- and B-type scaffold groups compared to MG group. (H,I) Quantification of the expression of NESTIN and PLZF. Scale bar, $50 \mu \mathrm{m}$. MG, Matrigel.
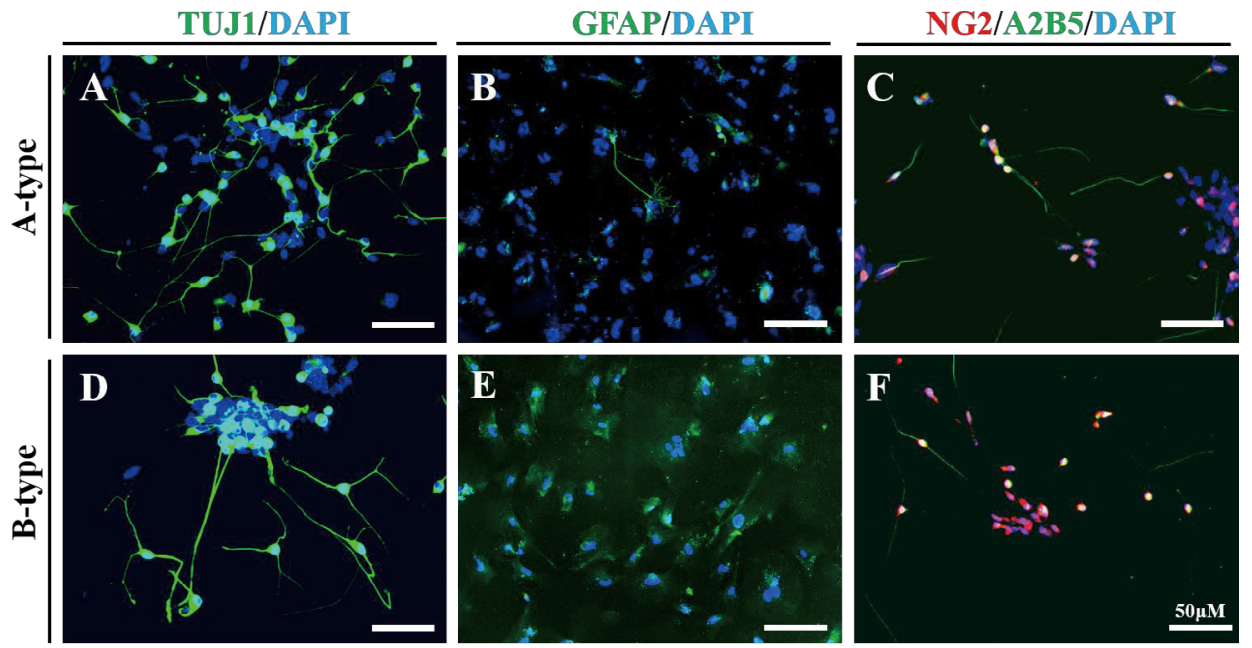

Fig. 3. Representative immunofluorescence images of neurons (TUJ1-positive) (A, D), astrocytes (GFAP. positive) (B, E), and oligodendrocyte precursors (NG2/A2B5-double positive) (C, F) differentiated on PVDF nanofiber scaffolds. Scale bar, $50 \mu \mathrm{m}$. 
positive cells and GFAP-positive cells. Thus, we concluded that NPs differentiated on the PVDF nanofiber scaffolds retain their differentiation potential as neural stem cells.

\section{Identification of highly variable genes in NPs differentiated on the PVDF nanofiber scaffolds}

Next, we performed comparative transcriptome analysis by RNAseq to explore the mechanism through which the PVDF nanofiber scaffold facilitated neural differentiation of hESCs. Hierarchical clustering showed that the two nanofiber scaffold groups were more closely related to each other than the Matrigel group (Fig. 4A); this was consistent with the results regarding the yield of SOX1-positive cells (Fig. 2D). We identified 45 genes with highest variation in expression across samples. Of those, 6 genes were upregulated exclusively in the Matrigel group and, among these, 3 genes had known gene annotations (in the green box of Fig. 4A and C; NELL2, CA4, and GRIN2B). In other words, NELL2, CA4, and GRIN2B were specifically downregulated in both the nanofiber scaffold groups. These genes play roles in protein kinase signaling, bicarbonate transport, and transportation of $\mathrm{Ca}^{2+}$ ions (Fig. $4 \mathrm{C}$ ). In contrast, 27 genes were upregulated in the nanofiber scaffold groups, of which three and seven genes were exclusive to the A-type group and B-type group, respectively (Fig. 4B). Two out of three genes in the A-type group had known GO-terms related to the regulation of transcription (VGLL3) and FGF receptor signaling pathway (FGFBP3) (orange region in Fig. 4A and C). Given that FGF signaling is essential for neural induction during vertebrate development (Wilson \& Edlund, 2001), upregulation of FGFBP3, a positive regulator of the FGF signal, might be the factor that enhances the efficiency of neural differentiation on the A-type nanofiber scaffold.

The gene-set specific for the B-type group included five genes (out of seven genes upregulated) that are related to neural cell proliferation (ATF5), cellular response to insulin (TRIB3), lipid

A

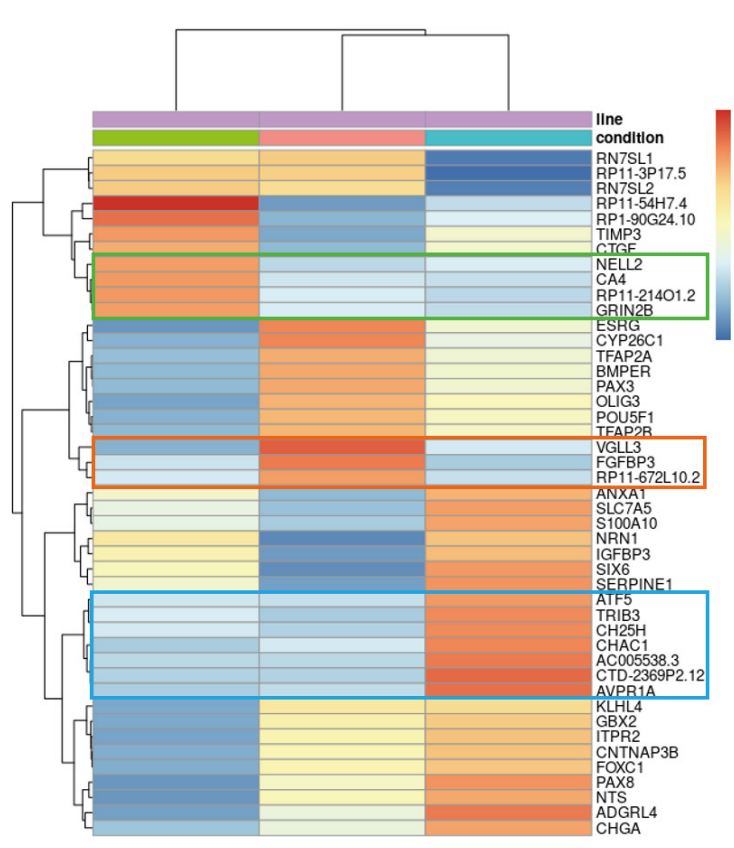

B

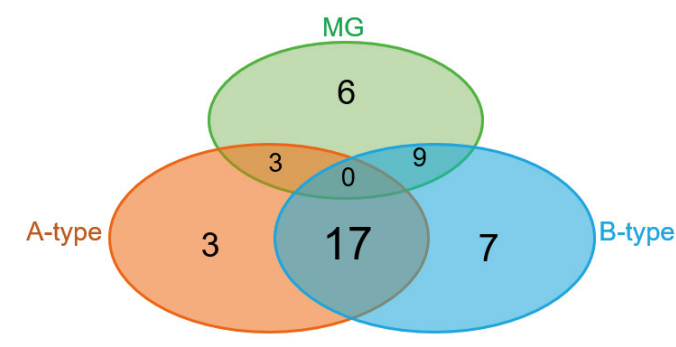

\section{C}

\begin{tabular}{|c|c|c|c|c|}
\hline & $\begin{array}{c}\text { Gene } \\
\text { Abbreviation } \\
\end{array}$ & Gene Full Name & GO: Biological Process & GO Term \\
\hline \multirow{3}{*}{$\begin{array}{c}\text { Matrigel } \\
\text { only }\end{array}$} & NELL1 & $\begin{array}{l}\text { Protein kinase c-binding } \\
\text { protein }\end{array}$ & neuron cellular homeostasis & GO:0000981 \\
\hline & CA4 & Carbonic anhydrase 4 & bicarbonate transport & GO:0015701 \\
\hline & GRIN2B & $\begin{array}{l}\text { Glutamate receptor } \\
\text { ionotropic, NMDA 2B } \\
\end{array}$ & $\begin{array}{c}\text { brain development; } \\
\mathrm{Ca}^{2+} \text { transmembrane import into cytosol } \\
\end{array}$ & $\begin{array}{l}\text { GO:0007420 } \\
\text { GO:0097553 } \\
\end{array}$ \\
\hline \multirow{2}{*}{$\begin{array}{l}\text { A-type } \\
\text { only }\end{array}$} & VGLL3 & $\begin{array}{l}\text { Transcription cofactor } \\
\text { vestigial-like protein } 3 \\
\end{array}$ & $\begin{array}{l}\text { regulation of transcription by } \\
\text { RNA polymerase II }\end{array}$ & GO:0006357 \\
\hline & FGFBP3 & $\begin{array}{l}\text { Fibroblast growth factor- } \\
\text { binding protein } 3 \\
\end{array}$ & $\begin{array}{l}\text { positive regulation of fibroblast growth factor } \\
\text { receptor signaling pathway }\end{array}$ & GO:0045743 \\
\hline \multirow{5}{*}{$\begin{array}{l}\text { B-type } \\
\text { only }\end{array}$} & ATF5 & $\begin{array}{l}\text { Cyclic AMP-dependent } \\
\text { transcription factor-5 }\end{array}$ & $\begin{array}{l}\text { cerebellar granule cell precursor } \\
\text { proliferation }\end{array}$ & GO:0021930 \\
\hline & TRIB3 & Tribbles homolog 3 & $\begin{array}{l}\text { positive regulation of protein binding; } \\
\text { cellular response to insulin stimulus }\end{array}$ & $\begin{array}{l}\text { GO:0032092 } \\
\text { GO:0032869 }\end{array}$ \\
\hline & $\mathrm{CH} 25 \mathrm{H}$ & Cholesterol 25-hydroxylase & lipid biosynthetic process & GO:0006629 \\
\hline & $\mathrm{CHAC} 1$ & $\begin{array}{l}\text { Glutathione-specific gamma } \\
\text {-glutarnylcyclotransferase } 1 \\
\end{array}$ & $\begin{array}{c}\text { neurogenesis; } \\
\text { glutathione biosynthetic process }\end{array}$ & $\begin{array}{l}\text { GO:0022008 } \\
\text { GO:0006750 }\end{array}$ \\
\hline & AVPR1A & Vasopressin V1a receptor & $\begin{array}{l}\text { G protein-coupled receptor signaling pathway; } \\
\qquad \mathrm{Ca}^{2+} \text { mediated signal }\end{array}$ & $\begin{array}{l}\text { GO:0007186 } \\
\text { GO:0019722 }\end{array}$ \\
\hline
\end{tabular}

Fig. 4. Comparative transcriptome analysis by RNAseq. (A) A heatmap showing genes upregulated in cells grown on various substrates. Green, orange, and blue boxes indicate genes exclusively upregulated in the cells differentiated on MG, A- and B-type scaffold, respectively. (B) Venn-diagram showing the number of genes that are differentially expressed among groups, (C) A list of genes that were exclusively upregulated in each substrate and GO term analysis. 
metabolism $(C H 25 H)$, glutathione biosynthesis (CHAC1), and G-protein-coupled receptor signaling pathway (AVPR1A) (blue region in Fig. 4C). The remaining 17 genes were shared by both the nanofiber scaffold groups (Fig. 4B, and Table 2). Among those, eight genes were expressed more highly in the A-type group than in the B-type group; the expression of the other nine genes was higher in the B-type group than in the A-type group (Table 2). A GO term search revealed that several of the identified genes are directly related to the development of the nervous system (e.g. CYP26C1, PAX3, OLIG3, GBX2, and PAX8). Other genes are known to be involved in biological processes, including development and morphogenesis (TFAP2A, POU5F1, and FOXC1), G protein-coupled receptor signaling (NTS and $A D G R L 4)$, and cellular signaling pathways that are relevant to neural induction (BMPER and TFAP2B). It is noteworthy that BMPER is upregulated in both the nanofiber scaffold groups. It has been a long-standing theory that the BMP signal inhibits neural induction (Wilson \& Edlund, 2001) and that activation of the ERK signal is required for the acquisition of neural fate during early vertebrate development (Kuroda et al., 2005). Since BMPER is known to play dual roles in both BMP inhibition (Kelley et al., 2009) and ERK

Table 2. GO terms for 17 genes that were commonly upregulated in nano-scaffold groups

\begin{tabular}{|c|c|c|c|c|}
\hline & $\begin{array}{c}\text { Gene } \\
\text { abbreviation }\end{array}$ & Gene full name & GO: Biological Process & GO term \\
\hline \multirow{8}{*}{$\begin{array}{l}\text { A-type } \\
\text { and } \\
\text { B-type } \\
(A>B)\end{array}$} & $E S R G$ & $\begin{array}{l}\text { Embryonic stem cell-related } \\
\text { gene protein }\end{array}$ & ND & NA \\
\hline & CYP26C1 & Cytochrome P450 26C1 & $\begin{array}{l}\text { Central nervous system development; } \\
\text { anterior/posterior pattern specification; } \\
\text { neural crest cell development }\end{array}$ & $\begin{array}{l}\text { GO: } 0007417 \\
\text { GO:0009952 } \\
\text { GO:0014032 }\end{array}$ \\
\hline & TFAP2A & $\begin{array}{l}\text { Transcription factor } \\
\text { AP-2alpha }\end{array}$ & $\begin{array}{l}\text { Trigeminal nerve development; } \\
\text { retina layer development }\end{array}$ & $\begin{array}{l}\text { GO:0021559 } \\
\text { GO:0010842 }\end{array}$ \\
\hline & $B M P E R$ & $\begin{array}{l}\text { BMP-binding endothelial } \\
\text { regulator protein }\end{array}$ & $\begin{array}{l}\text { Negative regulation of BMP signaling pathway; } \\
\text { positive regulation of ERK1 and ERK2 cascade }\end{array}$ & $\begin{array}{l}\text { GO:0030514 } \\
\text { GO:0070374 }\end{array}$ \\
\hline & PAX3 & Paired box protein-3 & $\begin{array}{l}\text { Animal organ morphogenesis; } \\
\text { nervous system development }\end{array}$ & $\begin{array}{l}\text { GO:0009887 } \\
\text { GO:0007399 }\end{array}$ \\
\hline & OLIG3 & $\begin{array}{l}\text { Oligodendrocyte } \\
\text { transcription factor } 3\end{array}$ & $\begin{array}{l}\text { Spinal cord motor neuron differentiation; } \\
\text { regulation of gene expression }\end{array}$ & $\begin{array}{l}\text { GO:0021520 } \\
\text { GO:0000122 }\end{array}$ \\
\hline & POU5F1 & $\begin{array}{l}\text { POU domain, class } 5 \\
\text { transcription factor } 1\end{array}$ & $\begin{array}{l}\text { Anatomical structure morphogenesis; } \\
\text { blastocyst development }\end{array}$ & $\begin{array}{l}\text { GO:0009653 } \\
\text { GO:0001824 }\end{array}$ \\
\hline & TFAP2B & $\begin{array}{l}\text { Transcription factor } \\
\text { AP-2beta }\end{array}$ & $\begin{array}{l}\text { Regulation of cell differentiation; } \\
\text { regulation of BMP signaling pathway }\end{array}$ & $\begin{array}{l}\text { GO:0045595 } \\
\text { GO:0030510 }\end{array}$ \\
\hline \multirow{9}{*}{$\begin{array}{l}\text { A-type } \\
\text { and } \\
\text { B-type } \\
(A<B)\end{array}$} & $K L H L 4$ & Kelch-like protein 4 & Actin binding & GO:0003779 \\
\hline & GBX2 & Homeobox protein GBX-2 & $\begin{array}{l}\text { Nervous system development; } \\
\text { hindbrain development; } \\
\text { forebrain neuron development }\end{array}$ & $\begin{array}{l}\text { GO:0007399 } \\
\text { GO:0030902 } \\
\text { GO:0021884 }\end{array}$ \\
\hline & ITPR2 & $\begin{array}{l}\text { Inositol 1,4,5-trisphosphate } \\
\text { receptor type } 2\end{array}$ & $\begin{array}{l}\text { Calcium ion transport; } \\
\text { cellular response to cAMP }\end{array}$ & $\begin{array}{l}\text { GO:0071320 } \\
\text { GO:0071320 }\end{array}$ \\
\hline & CNTNAP3B & $\begin{array}{l}\text { Contactin-associated } \\
\text { protein-like 3B }\end{array}$ & Cell adhesion & GO:0007155 \\
\hline & FOXC1 & Forkhead box protein $\mathrm{C} 1$ & $\begin{array}{c}\text { Anatomical structure morphogensis; } \\
\text { chemokine-mediated signaling pathway; } \\
\text { eye development }\end{array}$ & $\begin{array}{l}\text { GO:0009653 } \\
\text { GO:0070098 } \\
\text { GO:0001654 }\end{array}$ \\
\hline & PAX8 & Paired box protein-8 & $\begin{array}{l}\text { Anatomical structure morphogenesis; } \\
\text { central nervous system development; }\end{array}$ & $\begin{array}{l}\text { GO:0009653 } \\
\text { GO:0007417 }\end{array}$ \\
\hline & NTS & Neurotensin/neuromedin $\mathrm{N}$ & G protein-coupled receptor signaling pathway; & GO:0007186 \\
\hline & $A D G R L 4$ & $\begin{array}{l}\text { Adhesion G protein-coupled } \\
\text { receptor } L 4\end{array}$ & $\begin{array}{l}\text { Cell surface receptor signaling pathway; } \\
\text { adenylate cyclase-activating G protein-coupled } \\
\text { receptor signaling pathway }\end{array}$ & $\begin{array}{l}\text { GO:0007166 } \\
\text { GO:0007189 }\end{array}$ \\
\hline & CHGA & Chromogranin-A & $\begin{array}{l}\text { Negative regulation of neuron death; } \\
\text { protein localization to secretory granule }\end{array}$ & $\begin{array}{l}\text { GO:1901215 } \\
\text { GO:0003366 }\end{array}$ \\
\hline
\end{tabular}

ND, not determined; NA, not applicable; BMP, bone morphogenetic protein. 
activation (Heinke et al., 2013), its upregulation can be considered as one of the key factors that facilitate neural differentiation on PVDF nanofiber scaffolds. Collectively, our finding that genes upregulated in the nanofiber scaffold groups are highly related to neural development suggests that these genes might play a significant role in the enhanced neural differentiation on PVDF nanofiber scaffolds.

\section{DISCUSSION}

Dual-SMAD inhibition is to date the most efficient and powerful approach proposed for the neural differentiation of hESCs and forces hESCs to differentiate into cells of a neuroectodermal lineage without a choice to differentiate into cells of other lineages, such as endoderm, mesoderm, and even epidermal lineages (Chambers et al., 2009). This strategy was discovered and has been used on rigid and smooth plastic culture plates, yet it yielded a substantial percentage ( $\sim 80 \%$ of total cells, see reference (Chambers et al., 2009) and Fig. 2G) of SOX1-positive NPs in 8 days of differentiation. This robustness might be the reason why no other strategy significantly improves the efficiency of neural differentiation in combination with dual-SMAD inhibition.

The physical cues from the fibrous architecture of the extracellular environment have been intensively explored in culture techniques for stem cells, particularly for the facilitation of differentiation efficiency ( $\mathrm{Li}$ et al., 2014). In recent studies, researchers have produced nanofiber scaffolds with various biocompatible materials and showed that these scaffolds could replace the need of ECM substrates for neural differentiation of pluripotent stem cells (KarbalaeiMahdi et al., 2017; Silantyeva et al., 2018). These findings indicated the possibility that modulation of the extracellular environment may further increase the high efficiency of neural differentiation brought about by dual-SMAD inhibition.

In an attempt to devise a new synthetic microenvironment for the neural differentiation of hESCs, we fabricated a nanofiber scaffold with PVDF using the electrospinning technique. We were particularly interested in PVDF because of its unique piezoelectric property. Piezoelectricity is a quality of material asymmetry, which leads to the spontaneous generation of electric signals upon physical deformation (Li et al., 2019). Due to the unique arrangement of polar fluorine atoms within the vinylidene fluoride monomer (namely, $\beta$-phase), the electrospun nanofiber scaffold of PVDF is highly electroactive; thus, it has been used to culture or differentiate electrically active cells, such as cardiomyocytes and osteoblasts (Li et al., 2019). Based on the same concept, we hypothesized that PVDF nanofibers result in the formation of a scaffold that provides not only the fibrous microenvironment of brain tissue but also an electroactive substrate for the differentiation of neural cells from hESCs. Despite all its advantages, however, our previous observation indicated that the PVDF nanofiber scaffold is not compatible for the attachment of hESCs (unpublished). Therefore, we made a biochemical modification to PVDF for the adherence of hESCs by immobilizing a vitronectin peptide onto it through fusion with MAP combined with EDC/ NHS activation. As a result, hESCs were able to firmly adhere onto the nanofiber scaffolds. Most importantly, when hESCs were differentiated on the scaffolds under dual-SMAD inhibition, significantly more SOX1-positive NPs were generated on the scaffolds than on Matrigel. The NPs were able to differentiate into neurons, astrocytes, and oligodendrocyte precursors, indicating that the NPs completely retain their differentiation potential as neural stem cells.

Our comparative gene expression analysis revealed highly variable genes in the nanofiber scaffold groups. Among the 27 genes that were upregulated in the nanofiber scaffold groups, 17 genes were upregulated in both A- and B-type scaffolds, even though the extent of expression 
of individual genes differed slightly in each group. It was not surprising to see that majority of the genes (17/27 genes) were commonly upregulated in both the groups because both types of scaffolds were produced using the same technique (electrospinning) and the same material (PVDF). Nonetheless, we still found that 10 genes were exclusively upregulated in each scaffold group (3 genes in the A-type group and 7 genes in the B-type group). Because the only difference between the two scaffolds was the diameter of nanofiber, we infer that the topological effect of different diameters might have resulted in differential gene expression. In support of this idea, previous studies have shown that the fiber diameter of electrospun scaffolds influences differentiation of stem cells (Christopherson et al., 2009; Bean \& Tuan, 2015). These studies proposed that change in membrane nanostructure could affect the protein binding properties of the scaffold, which could subsequently alter cell morphology and differentiation potential. As shown in Fig. 1E and F, the morphology of hESCs was indeed different on the two nanofiber scaffolds. Therefore, we assume that the morphological changes in the cells grown on nanofiber scaffolds with different fiber diameters altered the differentiation kinetics of hESCs and thus resulted in differential gene expression between the two groups.

In summary, this study provides a new culture platform for the neural differentiation of hESCs. The PVDF nanofiber scaffolds coated with a peptide derived from vitronectin efficiently supported the attachment of hESCs and, most importantly, were able to enhance the efficiency of neural differentiation using the dual-SMAD strategy. Since this new platform can be produced in a highly defined manner and is composed of a stable and biocompatible material, we believe that it will serve as an advanced culture system for the production of neural cells for future biomedical applications.

\section{REFERENCES}

Akhmanova M, Osidak E, Domogatsky S, Rodin S, Domogatskaya A (2015) Physical, spatial, and molecular aspects of extracellular matrix of in vivo niches and artificial ccaffolds relevant to stem cells research. Stem Cells Int 2015:167025.

Bean AC, Tuan RS (2015) Fiber diameter and seeding density influence chondrogenic differentiation of mesenchymal stem cells seeded on electrospun poly( $\varepsilon$-caprolactone) scaffolds. Biomed Mater 10:015018.

Chambers SM, Fasano CA, Papapetrou EP, Tomishima M, Sadelain M, Studer L (2009) Highly efficient neural conversion of human ES and iPS cells by dual inhibition of SMAD signaling. Nat Biotechnol 27:275-280.

Christopherson GT, Song H, Mao HQ(2009) The influence of fiber diameter of electrospun substrates on neural stem cell differentiation and proliferation. Biomaterials 30:556-564.

Du ZW, Chen H, Liu H, Lu J, Qian K, Huang CL, Zhong X, Fan F, Zhang SC (2015) Generation and expansion of highly pure motor neuron progenitors from human pluripotent stem cells. Nat Commun 6:6626.

Heinke J, Juschkat M, Charlet A, Mnich L, Helbing T, Bode C, Patterson C, Moser M (2013) Antagonism and synergy between extracellular BMP modulators Tsg and BMPER balance blood vessel formation. J Cell Sci 126:3082-3094.

Hwang DS, Sim SB, Cha HJ (2007) Cell adhesion biomaterial based on mussel adhesive protein fused with RGD peptide. Biomaterials 28:4039-4046.

KarbalaeiMahdi A, Shahrousvand M, Javadi HR, Ghollasi M, Norouz F, Kamali M, Salimi A (2017) Neural differentiation of human induced pluripotent stem cells on polycaprolactone/gelatin bielectrospun nanofibers. Mater Sci Eng C Mater Biol Appl 78:1195-1202. 
Kelley R, Ren R, Pi X, Wu Y, Moreno I, Willis M, Moser M, Ross M, Podkowa M, Attisano L, Patterson C (2009) A concentration-dependent endocytic trap and sink mechanism converts Bmper from an activator to an inhibitor of Bmp signaling.J Cell Biol 184:597-609.

Kim DS, Lee JS, Leem JW, Huh YJ, Kim JY, Kim HS, Park IH, Daley GQ, Hwang DY Kim DW (2010) Robust enhancement of neural differentiation from human ES and iPS cells regardless of their innate difference in differentiation propensity. Stem Cell Rev Rep 6:270-281.

Klim JR, Li L, Wrighton PJ, Piekarczyk MS, Kiessling LL (2010) A defined glycosaminoglycanbinding substratum for human pluripotent stem cells. Nat Methods 7:989-994.

Kriks S, Shim JW, Piao J, Ganat YM, Wakeman DR, Xie Z, Carrillo-Reid L, Auyeung G, Antonacci C, Buch A, Yang L, Beal MF, Surmeier DJ, Kordower J H, Tabar V, Studer L (2011) Dopamine neurons derived from human ES cells efficiently engraft in animal models of Parkinson's disease. Nature 480:547-551.

Krueger F (2020) Trim galore. Available from https://github.com/FelixKrueger/TrimGalore. Accessed at Jan 20, 2020.

Kuroda H, Fuentealba L, Ikeda A, Reversade B, De Robertis EM (2005) Default neural induction: neuralization of dissociated Xenopus cells is mediated by Ras/MAPK activation. Genes Dev 19:1022-1027.

Lee BP, Messersmith PB, Israelachvili JN, Waite JH (2011) Mussel-inspired adhesives and coatings. Annu Rev Mater Res 41:99-132.

Li Y, Liao C, Tjong SC (2019) Electrospun polyvinylidene fluoride-based fibrous scaffolds with piezoelectric characteristics for bone and neural tissue engineering. Nanomaterials (Basel) 9:952.

Li Y, Liu M, Yan Y, Yang ST (2014) Neural differentiation from pluripotent stem cells: The role of natural and synthetic extracellular matrix. World J Stem Cells 6:11-23.

Love MI, Huber W, Anders S (2014) Moderated estimation of fold change and dispersion for RNA-seq data with DESeq2. Genome Biol 15:550.

Melkoumian Z, Weber JL, Weber DM, Fadeev AG, Zhou Y, Dolley-Sonneville P, Yang J, Qiu L, Priest CA, Shogbon C, Martin AW, Nelson J, West P, Beltzer JP, Pal S, Brandenberger R (2010) Synthetic peptide-acrylate surfaces for long-term self-renewal and cardiomyocyte differentiation of human embryonic stem cells. Nat Biotechnol 28:606-610.

Niklason LE (2018) Understanding the extracellular matrix to enhance stem cell-based tissue regeneration. Cell Stem Cell 22:302-305.

Palmer I, Wingfield PT (2004) Preparation and extraction of insoluble (inclusion-body) proteins from Escherichia coli. Curr Protoc Protein Sci 38:6.3.1-6.3.18.

Patro R, Duggal G, Love MI, Irizarry RA, Kingsford C (2017) Salmon provides fast and biasaware quantification of transcript expression. Nat Methods 14:417-419.

Perrier AL, Tabar V, Barberi T, Rubio ME, Bruses J, Topf N, Harrison NL Studer L (2004) Derivation of midbrain dopamine neurons from human embryonic stem cells. Proc Natl Acad Sci USA 101:12543-12548.

Silantyeva EA, Nasir W, Carpenter J, Manahan O, Becker ML Willits RK (2018) Accelerated neural differentiation of mouse embryonic stem cells on aligned GYIGSR-functionalized nanofibers. Acta Biomater 75:129-139.

Smith L,R, Cho S, Discher DE (2018) Stem cell differentiation is regulated by extracellular matrix mechanics. Physiology (Bethesda) 33:16-25.

Soneson C, Love MI, Robinson MD (2015) Differential analyses for RNA-seq: transcript-level estimates improve gene-level inferences. F1000Res 4:1521.

Wilson SI, Edlund T (2001) Neural induction: toward a unifying mechanism. Nat Neurosci 4:1161-1168. 
Zhang SC, Wernig M, Duncan ID, Brustle O, Thomson JA (2001) In vitro differentiation of transplantable neural precursors from human embryonic stem cells. Nat Biotechnol 19:11291133.

Zhou Y, Zhou B, Pache L, Chang M, Khodabakhshi AH, Tanaseichuk O, Benner C, Chanda SK (2019) Metascape provides a biologist-oriented resource for the analysis of systems-level datasets. Nat Commun 101523. 
